\title{
Article \\ Bowel Health in U.S. Vegetarians: A 4-Year Data Report from the National Health and Nutrition Examination Survey (NHANES)
}

\author{
Maximilian Andreas Storz ${ }^{1, *(\mathbb{C}}$, Gianluca Rizzo ${ }^{2}{ }^{(D}$, Alexander Müller ${ }^{1}$ and Mauro Lombardo ${ }^{3}$ \\ 1 Department of Internal Medicine II, Center for Complementary Medicine, Freiburg University Hospital, \\ Faculty of Medicine, University of Freiburg, 79106 Freiburg, Germany; \\ alexander.mueller@uniklinik-freiburg.de \\ 2 Independent Researcher, Via Venezuela 66, 98121 Messina, Italy; gianlucarizzo@email.it \\ 3 Department of Human Sciences and Promotion of the Quality of Life, San Raffaele Roma Open University, \\ 00166 Rome, Italy; mauro.lombardo@uniroma5.it \\ * Correspondence: maximilian.storz@uniklinik-freiburg.de
}

check for updates

Citation: Storz, M.A.; Rizzo, G.; Müller, A.; Lombardo, M. Bowel Health in U.S. Vegetarians: A 4-Year Data Report from the National Health and Nutrition Examination Survey (NHANES). Nutrients 2022, 14, 681. https://doi.org/10.3390/nu14030681

Academic Editor: Carol Johnston

Received: 22 January 2022

Accepted: 2 February 2022

Published: 6 February 2022

Publisher's Note: MDPI stays neutral with regard to jurisdictional claims in published maps and institutional affiliations.

Copyright: (c) 2022 by the authors. Licensee MDPI, Basel, Switzerland. This article is an open access article distributed under the terms and conditions of the Creative Commons Attribution (CC BY) license (https:// creativecommons.org/licenses/by/ $4.0 /)$.

\begin{abstract}
Dietary fiber is of paramount importance in the prevention of large-bowel diseases, yet fiber intake in many high income countries is well below daily recommendations. Vegetarian diets high in fiber-rich plant-foods have been associated with a higher frequency of bowel movements and softer stools. Thus, vegetarians appear to suffer less frequently from constipation and other bowel disorders. The number of studies investigating these associations, however, is limited. The present study sought to investigate bowel health and constipation prevalence in a self-identified vegetarian population from the U.S. National Health and Nutrition Examination Survey (2007-2010). Bowel health assessment included Bristol Stool Scale (BSS), Bowel Movement (BM) frequency and Fecal Incontinence Severity Index (FISI). The present study included 9531 non-vegetarians and 212 vegetarians. We found no associations between vegetarian status and all examined bowel health items (BM frequency, BSS and FISI). Vegetarians consumed significantly more fiber than omnivores (21.33 vs. $16.43 \mathrm{~g} / \mathrm{d}, p<0.001)$ but had a lower moisture intake ( $2811.15 \mathrm{vs.} 3042.78 \mathrm{~g} / \mathrm{d}, p=0.045)$. The lack of an association of vegetarian status and bowel health is surprising, and may be a result of the relatively low fiber intake in this particular vegetarian cohort, which did not meet the daily fiber recommendations.
\end{abstract}

Keywords: vegetarian; plant-based; fiber; bowel health; constipation; NHANES; bristol stool scale; stool

\section{Introduction}

Four decades ago, the famous Irish surgeon Denis P. Burkitt and his team recognized the important role of dietary fiber in the prevention of certain large-bowel diseases [1,2], which by now have become highly prevalent in the Western hemisphere [3-5]. Diets high in fiber result in large, soft stools that traverse the intestine rapidly, whereas fiber-deficient diets abundant in refined foods were linked to constipation and colon cancer [6].

Currently, dietary fiber intake in high income countries is approximately $15 \mathrm{~g} /$ day, and, as such, well below the amount of fiber Burkitt advocated for ( $>50 \mathrm{~g} /$ day) [5]. Diets low in fiber avoid or minimize beans, nuts, peas, lentils, legumes, brown rice, whole grains, nuts and seeds and emphasize well-cooked red meat, fish, poultry, eggs and certain dairy products [7]. Such diets have been occasionally recommended following bowel surgery or treatments (such as radiotherapy) that damage the digestive tract [8]. In many individuals, dietary fiber restriction results in a reduction in the size and frequency of stools [9].

Plant-based diets (including vegetarian and vegan diets), in contrast, are rich in fiberdense foods, including fruits, legumes and green leafy vegetables [10]. These diets influence gut motility and the composition of the human gut microbiota [11-14]. Although studied 
less frequently, several trials also suggested differences in defecation and stool patterns between vegetarians and non-vegetarians [11].

Vegetarian diet has been associated with a higher frequency of bowel movements and softer stools with fewer superficial cracks [15]. As such, vegetarians appear to be less frequently affected by (atonic) constipation [11,16], a widespread clinical condition that may negatively impact quality of life to a similar extent as musculoskeletal disorders, allergies and chronic inflammatory bowel disorders [17]. Some studies also suggested an inverse dose relationship between the amount of meat in diet and the frequency of defecation [18]. Vegetarian diets avoid meat and meat products [19] and, as a corollary, could therefore impact defecation frequency.

Several authors emphasized that vegetarian populations differ from omnivorous populations with regard to bowel habits and defecation patterns. However, the number of studies investigating these associations is limited, and up-to-date trials in current vegetarian populations are lacking. The fact that vegetarian populations around the globe also differ significantly with regard to their actual dietary patterns also warrants consideration in this discussion. As such, it appears of paramount importance to investigate bowel health across different vegetarian populations.

We conducted a serial cross-sectional analysis of data from the National Health and Nutrition Examination Survey (NHANES) to characterize bowel health in U.S. vegetarians. The aims of this cross-sectional study were two-fold: (a) to investigate the prevalence of constipation in a well-characterized sample of U.S. vegetarians [20] and (b) to gain additional insights into defecating function in this particular cohort.

\section{Materials and Methods}

\subsection{The NHANES}

The NHANES is a cross-sectional, complex population-based survey with multiple components (including in-person interviews, laboratory and clinical examinations) [21]. NHANES is administered by the National Center for Health Statistics (NCHS) of the Centers for Disease Control on Prevention (CDC) [22]. The survey examines a nationally representative sample of approximately 5000 individuals annually. The sample for the survey is selected to represent the U.S. population of all ages. To produce reliable statistics and population estimates, NHANES oversamples certain groups, e.g., individuals aged 60 or older, African Americans and Hispanics.

One of the key NHANES features is the complex multistage, stratified, clustered and probability sampling design [23] that warrants special attention when analyzing NHANES data [24]. When analyzing NHANES data, weighting is of utmost importance to make reliable estimates that are representative of the U.S. civilian non-institutionalized population [25]. For this particular analysis, we appended 2 consecutive NHANES survey cycles (2007-2008 and 2009-2010). These cycle were chosen because both included a (selfreported) "vegetarian status" variable (see below) that divided the cohort in two groups: vegetarians and non-vegetarians. All NHANES survey protocols were approved by the NCHS Research Ethics Review Board.

\subsection{Covariates}

Data to describe both populations (vegetarians and non-vegetarians) stem from questionnaire-based personal interviews at participants' homes, followed by visits at a NHANES mobile examination center (MEC) [26]. NHANES interviews cover demographic, dietary, socioeconomic and other health-related questions. For the purpose of this analysis, we merged demographic data, examination data and questionnaire data with dietary data.

Demographic data included gender (female/male), age (in years) and ethnicity $[27,28]$. Race/ethnicity comprised five categories including "Mexican American," "non-Hispanic White," "non-Hispanic Black," "other Hispanic" and "Other Race" (includes mixed race). In addition, we investigated annual household income and marital status. The latter comprised three categories, including "married/living with a partner," "wid- 
owed/divorced/separated" and "never married." Vegetarian status was self-reported and based on the question: "do you consider yourself to be a vegetarian?"

Dietary data included daily calorie intake as well as macronutrient intake, fiber intake, caffeine intake, alcohol intake and daily aggregates of water (moisture) $[29,30]$. The latter included all moisture present in foods and beverages, including tap and bottled waters consumed as beverages. A previous analysis of NHANES vegetarians revealed that this cohort consumed, on average, significantly fewer calories than their omnivorous counterparts [20]. As such, we made use of a commonly used energy adjustment method to account for these difference in energy intake. We expressed nutrient density as intake (in gram or milligram) per $1000 \mathrm{kcal}$. Adjustment for total energy intake is frequently performed in epidemiological studies to minimize extraneous variation and to control for confounding factors [31,32]. The study by Juan and colleagues already included a detailed food group analysis in U.S. vegetarians [20], and as such we refrained from repeating this part. The aforementioned subset of dietary parameters was chosen because all variables (fiber, moisture, fat intake, etc.) have been previously associated with constipation and bowel health in general $[33,34]$. All dietary data were obtained from the dietary interview component $[29,30]$. This module uses a computerized $24 \mathrm{~h}$ dietary recall method to estimate energy and nutrient intake for all participants. A detailed description of the dietary data collection instrument (the so-called Automated Multiple Pass Method (AMPM)) can be obtained from the homepage of the U.S. Department of Agriculture [35]. For interested readers, the examination protocol and data collection methods are fully documented in the NHANES dietary interviewer's procedure manuals [36].

Examination data were limited to anthropometric measurements including body mass index (BMI). We categorized BMI into for commonly used groups: obesity (BMI $\geq 30$ ), overweight (BMI 25-29.99), normal weight (BMI 18.5-24.99) and underweight (BMI $\leq 18.49$ ). All body measurement data were collected by trained health technicians with the support of a recorder during the body measurement examination $[37,38]$.

\subsection{Bowel Health Assessment}

In order to explore the prevalence of constipation and to assess defecating function in U.S. vegetarians, we used data from the Bowel Health section of the mobile exam center (MEC) interview. The Bowel Health Questionnaire (variable name prefix BHQ) provides personal interview data on defecating function and fecal incontinence for adults age 20 years and older [39,40]. First administered in the NHANES in 2005, the 2007/2008 component comprised 6 questions. Based on the Fecal Incontinence Severity Index (FISI) by Rockwood et al. [41], 4 questions assessed adult incontinence leakage. The symptoms composing the index are incontinence of liquid stool, solid stool, gas and mucus [39]. The questions apply a type $x$ frequency matrix to obtain the subject's perception of symptom severity.

We assessed stool frequency using the following interview question: "How many times do you have a Bowel Movements (BM) per week?" We recorded BMs into five subgroups following the approach by Mitsuhashi and colleagues [42], which comprised $<3$, $\geq 3-7, \geq 8-14, \geq 15-21$ and $\geq 21$ BMs per week. All categories were determined based on logical cutpoints ( $\geq 3-7=$ up to one BM per day; $\geq 8-14=$ one to two BMs per day; $\geq 15-21$ $=$ two to three BMs per day; $\geq 21$ more than 3 BM per day).

An additional question included the Bristol Stool Form Scale (BSFS) [43]. The stool consistency scale has been used in a series of clinical studies to assess stool form in several gastrointestinal disorders [44]. BSFS demonstrated substantial validity and reliability [45]. Stool consistency was assessed using BSFS (BSFS: range from type 1-7). Participants were asked to define their stool by recording the number type that corresponded to their usual/most common stool type. BSFS demonstrated fair correlation with colonic transit time (CTT) and a BSFS of 1-2 has been suggested as a surrogate for delayed CTT in Westerners [46]. On the other hand, studies also found the BSFS score to correlate with the severity of incontinence [47]. Based on these findings, we defined constipation and diarrhea 
based on self-reported typical stool type. Following the approach of Wilson [48], stool type 1 (separate hard lumps, similar to nuts) and stool type 2 (sausage-like, but lumpy) on the BSFS were defined as constipation. Stool type 6 (fluffy pieces with ragged edges, a mushy stool) and stool type 7 (watery, no solid pieces) were defined as diarrhea.

Fecal incontinence (FI) was defined based on a previous study by Ditah and colleagues [49]. FI was defined as any involuntary loss or accidental leakage of mucus, liquid or solid stool during the past 30 days. The employed definition of FI did not include gas leakage, which we analyzed separately. Accidental bowel leakage was defined as leaking from the bowel or intestines that cannot be controlled.

\subsection{Statistical Analysis}

All statistical analyses were conducted using STATA version 14 (StataCorp., College Stadion, TX, USA). We used the "svyset" and "svy" commands for all statistical procedures to properly account for population weights and the complex NHANES survey design characteristics. These weights take into account unequal probabilities of selection resulting from the sample design, non-response and planned over-sampling of the elderly; non-Hispanic Blacks; and Mexican Americans [50]. Following NHANES guidelines, we generated a 4-year weight (2007-2010) to obtain weighted percentages adjusted to the US adult population. All variables were compared between self-identified vegetarians and non-vegetarians.

We described normally distributed variables with their mean and standard error in parentheses, whereas non-normally distributed variables are presented as median and interquartile range in parentheses. To describe categorical variables, we reported the number of observations (n) as well as weighted proportions (with their corresponding standard error) in parenthesis.

In order to make statistically valid population inferences from sample data, we computed standard errors using procedures that took into account the complex nature of the sample design [51]. Continuous (normally distributed) variables were compared by using appropriate sample weights for two-sample Student's t-tests. For categorical variables, we used STATA's design-adjusted Rao-Scott test (a design-adjusted version of the Pearson chi-square test) to explore potential associations between vegetarian status and the respective variables. Statistical significance was determined at $\alpha=0.05$. All tests for statistical significance were two-sided.

To determine the reliability of estimated proportions, we followed the strict recommendations of NCHS [52]. In order to assess the reliability of a proportion, we used the postestimation command "kg_nchs" in STATA [53]. Following the svy: proportion command "kg_nchs" allows users to calculate Korn-Graubard Confidence Intervals (CI) and to display a series of three dichotomous flags that show if NCHS standards are met. The command indicates whether the respective proportion (p) (and the complementary proportion (1-p)) meets all presentation standards and is considered reliable. Proportions that did not meet the NCHS standard ("unreliable proportions", e.g., when the standard error exceeded $30 \%$ of the proportion estimate or when the relative CI width exceeded $130 \%$ of the proportion) were clearly marked for all tables.

\section{Results}

The present study included 9743 individuals (unweighted) with a complete dataset. Of these, $n=9531$ were non-vegetarians and $n=212$ were self-identified vegetarians. Table 1 shows demographic, anthropometric and other characteristics of our sample. The weighted vegetarian subpopulation comprised significantly more females compared to the non-vegetarian group $(68.24 \%$ vs. $50.82 \%, p<0.001)$. Although vegetarians tended to be slightly younger, we observed no significant differences with regard to mean age in both groups $(p=0.195)$.

Vegetarian status was not independent of ethnicity and education level $(p<0.001$ and $p=0.001$ ), as assessed by the design-adjusted Rao-Scott test (Table 1). The weighted 
proportion of vegetarians with a college degree (or higher) was significantly larger as compared to non-vegetarians $(42.36 \%$ vs. $27.02 \%, p=0.006)$. In contrast, the weighted proportion of individuals with "only" a high school degree was significantly higher in the non-vegetarian group $(24.17 \%)$.

Table 1. Subgroup analysis of demographic, anthropometric and clinical characteristics by vegetarian status in individuals aged 20 years or older.

\begin{tabular}{|c|c|c|c|}
\hline Demographic, Anthropometric and Clinical Characteristics & $\begin{array}{l}\text { Non-Vegetarians } \\
n=9531\end{array}$ & $\begin{array}{l}\text { Vegetarians } \\
n=212\end{array}$ & $p^{\mathrm{a}}$ \\
\hline \multicolumn{4}{|l|}{ Gender } \\
\hline Female & $4785(50.82(0.44))$ & $130(68.24(3.62))^{\mathrm{a}}$ & \multirow[t]{2}{*}{$<0.001$} \\
\hline Male & $4746(49.18(0.44))$ & $82(31.76(3.62))^{\mathrm{a}}$ & \\
\hline Age (years) & $46.93(0.36)$ & $44.56(1.83)$ & 0.195 \\
\hline \multicolumn{4}{|l|}{ Ethnicity } \\
\hline Mexican American & $1659(8.25(1.31))$ & $34(6.52(1.68))$ & \multirow{5}{*}{$<0.001$} \\
\hline Other Hispanic & $956(4.64(0.81))$ & $27(4.93(1.18))^{\mathrm{c}}$ & \\
\hline Non-Hispanic White & $4746(71.01(2.35))$ & $91(62.51(6.81))$ & \\
\hline Non-Hispanic Black & $1810(10.91(1.08))$ & $29(7.73(1.86))$ & \\
\hline Other Race-Including Multi-Racial & $360(5.18(0.51))$ & $31(18.30(5.73))^{a, c}$ & \\
\hline \multicolumn{4}{|l|}{ Education level } \\
\hline Less than 9th grade & $1593(12.92(0.72))$ & $22(7.94(1.95))^{a}$ & \multirow{5}{*}{0.001} \\
\hline $9-11$ th grade $b$ & $2303(24.17(0.86))$ & $27(12.77(3.79))^{a, c}$ & \\
\hline High school graduate/GED or equivalent & & & \\
\hline Some college or AA degree & $2650(30.28(0.67))$ & $57(28.53(3.88))$ & \\
\hline College graduate or above & $1918(27.02(1.28))$ & $69(42.36(5.41))^{\mathrm{a}}$ & \\
\hline \multicolumn{4}{|l|}{ Marital Status } \\
\hline Married/living with partner & $5775(64.46(1.09))$ & $120(55.92(5.25))$ & \multirow{3}{*}{0.23} \\
\hline Widowed/divorced/separated & $2170(18.25(0.56))$ & $55(23.07(4.08))$ & \\
\hline Never married & $1586(17.30(0.90))$ & $37(21.01(4.62))$ & \\
\hline \multicolumn{4}{|l|}{ Annual household income } \\
\hline Under $\$ 20,000$ & $2071(14.44(0.84))$ & $51(17.06(4.14))$ & \multirow[t]{2}{*}{0.462} \\
\hline Over $\$ 20,000$ & $7460(85.56(0.84))$ & $161(82.94(4.14))$ & \\
\hline \multicolumn{4}{|l|}{ Smoking Status } \\
\hline Never smoker & 4991 (53.77 (1.17)) & $136(63.77(5.27))$ & \multirow{3}{*}{0.036} \\
\hline Former Smoker & $2407(24.69(0.78))$ & $55(25.32(3.75))$ & \\
\hline Current Smoker & $2133(21.54(0.79))$ & $21\left(10.91(2.98)^{a}\right.$ & \\
\hline \multicolumn{3}{|l|}{ Body mass index (BMI) } & \multirow[t]{5}{*}{0.001} \\
\hline Underweight $(\mathrm{BMI} \leq 18.49)$ & $137(1.43(0.18))$ & $5(4.47(2.21))^{\mathrm{c}}$ & \\
\hline Normal weight (BMI 18.5-24.99) & $2464(28.57(0.78))$ & $83(43.59(4.32))^{a}$ & \\
\hline Overweight (BMI 25-29) & $3237(33.85(0.69))$ & $70(33.34(3.84))$ & \\
\hline Obese $(\mathrm{BMI} \leq 30)$ & $3693(36.14(0.71))$ & $54(18.60(3.69))^{a}$ & \\
\hline
\end{tabular}

Legend for Table 1: $n=$ number of observations with weighted proportions in parenthesis. ${ }^{\text {a }}=$ indicates statistically significant differences in the proportions. ${ }^{b}=$ includes 12 th grade with no diploma. ${ }^{c}=$ estimate considered unreliable per NHCS analytic guidelines.

In addition to that, our results suggest no association between vegetarian status and marital status and annual household income, respectively ( $p=0.230$ and 0.462 ). The weighted proportion of current smokers, however, was significantly smaller in the vegetarian group (10.91\% vs. $21.54 \%)$. Furthermore, vegetarian status was also significantly associated with body mass index $(p=0.001)$. The weighted proportion of individuals with a normal weight was significantly higher in the vegetarian group $(43.59 \%$ vs. $28.57 \%$, $p=0.001)$, whereas the proportion of obese individuals was significantly smaller $(18.60 \%$ vs. $36.14 \%, p<0.001)$. 
When discussing these particular results, we believe it is important to highlight again that we followed the strict recommendations of NCHS to determine the reliability of the (weighted) estimated proportions [52]. In light of the limited number of observations with a full dataset in the vegetarian group $(n=212)$, some of the reported estimated proportions should be considered unreliable per NHCS analytic guidelines (e.g., the weighted proportion of underweight vegetarians, where the standard error exceeded $30 \%$ of the proportion estimate).

Table 2 compares nutrient intake by vegetarian status. Vegetarians consumed significantly fewer calories compared to non-vegetarians (1956.01 vs. $2185.96 \mathrm{kcal} / \mathrm{d}, p=0.024$ ). Energy-adjusted protein intake and fat intake were significantly higher in the non-vegetarian group, whereas energy-adjusted carbohydrate intake was higher in the vegetarian group. Of note, we also found a significant difference with regard to fiber intake $(p<0.001)$. Vegetarians consumed, on average, $21.33 \mathrm{~g}$ of fiber per day, whereas non-vegetarians consumed on average $16.43 \mathrm{~g}$ of fiber per day. We also observed a significant difference with regard to daily aggregates of water (including all moisture present in foods and beverages) between both groups. The latter was significantly higher in non-vegetarians (3042.78 g/d vs. $2811.15 \mathrm{~g} / \mathrm{d}, p=0.045)$.

Table 2. Nutrient intake analysis by vegetarian status in individuals aged 20 years or older. $n=$ number of observations. We present data as mean + standard error proportions in parenthesis.

\begin{tabular}{llll}
\hline Dietary Intake & $\begin{array}{l}\text { Non-Vegetarians } \\
\boldsymbol{n}=\mathbf{9 5 3 1}\end{array}$ & $\begin{array}{l}\text { Vegetarians } \\
\boldsymbol{n}=\mathbf{2 1 2}\end{array}$ & $\boldsymbol{p}^{\mathbf{a}}$ \\
\hline Energy value $(\mathrm{kcal}) / \mathrm{day}$ & $2185.96(17.62)$ & $1956.01(94.10)$ & 0.024 \\
\hline Protein $(\mathrm{g} / 1000 \mathrm{kcal})$ & $39.32(0.22)$ & $33.18(0.92)$ & $<0.001$ \\
\hline Carbohydrate $(\mathrm{g} / 1000 \mathrm{kcal})$ & $121.72(0.60)$ & $141.11(2.47)$ & $<0.001$ \\
\hline Fat $(\mathrm{g} / 1000 \mathrm{kcal})$ & $37.40(0.17)$ & $33.20(1.04)$ & $<0.001$ \\
\hline Fiber $(\mathrm{gm} / 1000 \mathrm{kcal})$ & $7.99(0.11)$ & $11.43(0.48)$ & $<0.001$ \\
\hline Fiber $(\mathrm{gm})$ & $16.43(0.28)$ & $21.33(1.21)$ & $<0.001$ \\
\hline Alcohol $(\mathrm{g} / \mathrm{d})$ & $11.78(0.572)$ & $8.12(2.41)$ & 0.146 \\
\hline Caffeine $(\mathrm{mg} / \mathrm{d})$ & $188.33(5.91)$ & $166.77(24.06)$ & 0.356 \\
\hline Moisture $(\mathrm{g} / \mathrm{d})$ & $3042.78(25.31)$ & $2811.15(17.55)$ & 0.045 \\
\hline
\end{tabular}

Legend for Table 2: Normally distributed variables are shown with their mean and standard error in parentheses.

Table 3 displays the examined bowel health items by vegetarian status. Our data suggest that all examined items (including BSS assessment, bowel movement frequency, fecal incontinence and bowel leakage) were independent of vegetarian status.

We observed no significant difference in the weighted proportion of vegetarians and non-vegetarians with a normal stool pattern (85.46\% vs. $85.60 \%$, as assessed by the BSFS). The number of self-identified vegetarians with a BSFS type 1 or type 2 stool was too small to predict a reliable weighted proportion (unweighted number of observations: $n=6$ and $n=10$, respectively). Importantly, almost $7.5 \%$ of the weighted non-vegetarian population suffered from constipation and approximately $7 \%$ suffered from diarrhea.

The weighted proportion of vegetarians with 3-7 bowel movements per week and 8-14 bowel movements per week was $61.46 \%$ and $28.73 \%$ (Table 3 ). Comparable numbers were observed in the non-vegetarian population. The weighted proportion of individuals with less than three bowel movements per week in the non-vegetarian group was almost $3.5 \%$. Again, the data distribution did not allow for a reliable prediction of that particular proportion in the vegetarian group (unweighted number of observations: $n=4$ ). 
Table 3. Bowel health by vegetarian status in individuals aged 20 years or older.

\begin{tabular}{|c|c|c|c|}
\hline Bowel Health Characteristics & $\begin{array}{l}\text { Non-Vegetarians } \\
n=9531\end{array}$ & $\begin{array}{l}\text { Vegetarians } \\
n=212\end{array}$ & $p^{\mathrm{a}}$ \\
\hline \multicolumn{4}{|l|}{ Bristol Stool Scale } \\
\hline Type 1 & $211(1.97(0.12))$ & $6(4.16(2.40))^{b}$ & \multirow{7}{*}{0.330} \\
\hline Type 2 & $521(5.36(0.34))$ & $10(2.78(1.17))^{a, b}$ & \\
\hline Type 3 & $2293(26.22(0.46))$ & $46(27.53(3.59))$ & \\
\hline Type 4 & $4899(51.28(0.92))$ & $106(47.86(4.67))$ & \\
\hline Type 5 & $818(8.09(0.42))$ & $23(10.06(2.80))$ & \\
\hline Type 6 & $688(6.31(0.31))$ & $19(7.25(1.77))$ & \\
\hline Type 7 & $101(0.75(0.11))$ & $2(0.35(0.25))^{b}$ & \\
\hline \multicolumn{4}{|l|}{ BSS-based stool pattern } \\
\hline Constipation & $732(7.33(0.34))$ & $16(6.94(2.55))^{b}$ & \multirow{3}{*}{0.919} \\
\hline Normal & $8010(85.60(0.47))$ & $175(85.46(3.65))$ & \\
\hline Diarrhea & $789(7.07(0.30))$ & $21(7.60(1.80))$ & \\
\hline \multicolumn{4}{|l|}{ Bowel Movement Frequency } \\
\hline$<3 /$ week & $339(3.41(0.32))$ & $4(2.28(1.42))^{b}$ & \multirow{5}{*}{0.774} \\
\hline 3-7/week & $5846(64.02(0.65))$ & $125(61.46(3.78))$ & \\
\hline 8-14/week & $2677(26.36(0.59))$ & $67(28.73(2.61))$ & \\
\hline$\geq 15-21 /$ week & $535(4.98(0.27))$ & $13(6.18(1.98))^{b}$ & \\
\hline$\geq 21 /$ week & $134(1.21(0.14))$ & $3(1.35(0.99))^{b}$ & \\
\hline \multicolumn{4}{|l|}{ Bowel leakage: gas } \\
\hline 2 or more times a day & $964(9.99(0.64))$ & $20(8.95(2.07))$ & \multirow{6}{*}{0.668} \\
\hline Once a day & $831(9.11(0.46))$ & $20(9.19(2.52))$ & \\
\hline 2 or more times a week & $681(7.38(0.34))$ & $18(7.04(1.82))$ & \\
\hline Once a week & $499(5.92(0.24))$ & $13(6.52(2.32))^{b}$ & \\
\hline 1-3 times a month & $1100(11.99(0.39))$ & $25(7.80(2.48))^{\mathrm{b}}$ & \\
\hline Never & $5456(55.59(0.86))$ & $116(60.50(4.06))$ & \\
\hline \multicolumn{4}{|l|}{ Fecal Incontinence (FISI) } \\
\hline Yes & $227(1.89(0.17)$ & $9(3.76(1.40))^{b}$ & \multirow[t]{2}{*}{0.085} \\
\hline No & $9304(98.11(0.17)$ & $203(96.24(1.40))$ & \\
\hline
\end{tabular}

Ultimately, we observed no significant intergroup differences in the weighted proportion of individuals with bowel leakage (gas). The weighted proportion of vegetarians "never" leaking gas was slightly higher; however, the results were not statistically significant. The weighted proportion of individuals with fecal incontinence was also slightly higher in the vegetarian group; yet again, the results were not statistically significant (Table 3).

\section{Discussion}

The present study sought to investigate bowel health and constipation prevalence in a self-identified vegetarian population from NHANES (2007-2010). Previous studies revealed significant differences with regard to form and stool consistency as well as bowel movement frequency and constipation prevalence between vegetarians and non-vegetarians. Surprisingly, the present study could not confirm the aforementioned findings.

Our study revealed no associations between vegetarian status and all examined bowel health items, including stool consistency, bowel movement frequency and constipation prevalence. This comes at a surprise and warrants a further discussion as well as a closer look at the nutrient intake in both groups.

A plant-based diet contains substantially larger amounts of dietary fibers than nonvegetarian diets [11]. In 1986, Davies et al. investigated bowel function measurements of individuals with different eating patterns [15]. Fifty-one individuals (ten women and seven men who habitually consumed an omnivorous, vegetarian or vegan diet) were examined. 
Vegans had the highest fiber intake (47 g), followed by vegetarians ( $37 \mathrm{~g}$ ) and those consuming an omnivorous diet ( $23 \mathrm{~g}$ ). While mean gut transit time was comparable across all three groups, vegans passed more frequent and softer stools. Lacto-Ovo-Vegetarians passed stool more frequently (1.2 \pm 0.5 stools per day) than non-vegetarians $(1.0 \pm 0.2$ stools per day). The highest frequency was observed in vegans ( $1.7 \pm 0.9$ stools per day) The authors also reported that increasing dietary fiber was associated with a shorter transit, more frequent stools and softer forms. Compared to our cohort, the vegetarian cohort in the study by Davies et al. [15] consumed substantially more fiber (37 g/d vs. $21.33 \mathrm{~g} / \mathrm{d}$ ). This might (partially) explain why the authors observed significant intergroup differences, while we did not.

Another cross-sectional analysis from the United Kingdom using data from the European Prospective Investigation into Cancer and Nutrition, Oxford cohort (EPIC-Oxford), demonstrated comparable trends [54]. Sanjoaquin et al. analyzed bowel movement frequency in 20,630 men and women aged 22-97 years. Compared with participants who regularly ate meat (9.5 in men, 8.2 in women), mean bowel movement frequency was higher in vegetarians (10.5 in men, 9.1 in women) and especially in vegans (11.6 in men, 10.5 in women) [54]. Again, the authors observed significant positive associations between bowel movement frequency and intakes of dietary fiber. In this study, the odds of having daily bowel movements also increased with increasing fiber intake for both genders, with an odds ratio in the highest compared with the lowest intake category of 2.00 (95\% CI: 1.38-2.90) in men and 1.43 (95\% CI: 1.24-1.64) in women. Again, unlike in our study, significant intergroup differences between plant-based eaters and omnivores were found.

Significant differences between vegetarians and non-vegetarians were also found in an Indian study by Panigrahi and colleagues [55]. Vegetarians tended to pass stool more frequently than non-vegetarians $(11.8 \pm 4.5$ vs. $11.3 \pm 4.7 ; p<0.05)$. Unfortunately, the exact amount of fiber intake per day was not assessed by the authors.

The authors of all three aforementioned studies found significant intergroup differences between vegetarians and non-vegetarians. Surprisingly, our study could not confirm this. The reasons for this warrant further discussion. At first, it is noteworthy that fiber intake in NHANES vegetarians is rather low (approximately $21 \mathrm{~g} / \mathrm{d}$ ) for this particular eating pattern. Self-identified NHANES vegetarians consumed a more plant-based diet than the U.S.: general population but differed from other "classical" (highly adherent) vegetarian populations in that they also occasionally consumed meat and fish [56].

As such, vegetarians in other cohorts, such as the French NutriNet-Santé cohort [57] or a comparable Belgian cohort, consumed substantially more fiber [58]. Vegetarians in our cohort, in turn, did not meet the Institute of Medicine's recommendations for fiber intake (adequate intake: $14 \mathrm{~g} / 1000 \mathrm{kcal}$ per day), highlighting once more America's substantial fiber gap [59]. This could be an important factor when discussing our results, as fiber obviously increases stool frequency in most individuals (particularly in those with constipation) [60].

Moreover, vegetarians in our cohort consumed less daily aggregates of water (moisture) than omnivores (Table 2). This included all moisture present in foods and beverages, including tap and bottled waters consumed as beverages. An adequate intake of fluid is necessary to enhance the effect of fiber in stool frequency regulation $[61,62]$. The fact that vegetarians in our sample consumed significantly less moisture than non-vegetarians may also explain why we observed no significant intergroup differences. Most other studies that investigated stool morphology and defecation patterns in vegetarian cohorts did not routinely report total moisture intake $[15,18,55]$. Only Sanjoaquin et al. reported fluid intake (including water and juices, but excluding milk, tea, coffee, soft drinks and alcoholic beverages) [54]. As such, a comparison to the other available studies remained difficult.

Third, Juan et al. already emphasized that a modest proportion of self-identified vegetarians in the NHANES occasionally reported consuming some type of animal products, such as meat, poultry and/or seafood [20]. As discussed before, some authors observed an inverse dose relationship between the amount of meat in diet and the frequency of defeca- 
tion $[18,63]$. The fact that a modest proportion of self-identified vegetarians in this sample consumed meat may have also contributed to the non-significant intergroup differences with regard to defecation.

Finally, we acknowledge that some of our proportion estimates must be considered "unreliable" with regard to recent NCHS guidelines [52], and as such we were unable to reliably estimate the proportion of U.S. vegetarians suffering from constipation. Thus, in light of the low (unweighted) number of vegetarians with constipation (or BSFS stool type 1 or 2), we could not reliably answer all of our study questions.

Nevertheless, our study draws upon a number of strengths. First, we present a nationally representative and large dataset (National Health and Nutrition Examination Survey) in a field (defection and stool patterns in vegetarians) that received comparably little attention in the past years. Second, the employed methods and tools (including BSFS and FISI) demonstrated substantial validity and reliability in previous studies, which is important when comparing different populations. Third and probably most important, the present study reminds us once more of the fact that not all plant-based diets are created equal [64] and that vegetarian populations differ substantially around the globe [65]. This is particularly important with regard to fiber intake in our vegetarian cohort, which was well below the fiber intake in other non-US vegetarian cohorts $[57,58,66]$. As such, reporting our results appears important and shows that being a self-reported vegetarian does not equal adequate fiber intake per sé.

At the same time, our study has several weaknesses worth mentioning. Despite the large, population-based sample, we identified a relatively small number of individuals with a complete dataset that identified themselves as vegetarians $(n=212)$. Our sample may be extrapolated to represent $2.12 \%$ of the U.S. vegetarian population (weighted), which is slightly less than the estimated vegetarian population in $2008(3.2 \%)$ in another study [67]. Unfortunately, the small sample size limits the precision of our estimates. In fact, estimates for some proportions in the vegetarian group should be considered unreliable per NCHS analytic guidelines (August 2017), as the standard error estimate exceeded 30\% of the proportion estimate (or because the relative confidence interval width exceeded $130 \%$ of the proportion). This applies for several proportions (e.g., BSFS Type 1 and 2, BSS-based constipation and some proportions of the bowel movement frequency variable), and we clearly acknowledge this limitation of our study. Usage of STATA's postestimation command "kg_nchs" enabled us to clearly identify the estimated proportions where this was the case. As such, not all our estimates are reliable and we had to focus our discussion on the ones that fulfilled the strict NCHS criteria.

Nevertheless, we refrained from reporting unweighted proportions (a frequently encountered alternative approach) and followed NCHS guidelines that mandate the use of sampling weights and sample design variables to obtain unbiased estimates and accurate standard errors. As such, some findings must be interpreted with caution. Yet, we believe it is important to report this data, highlighting the need for additional studies to characterize bowel health in U.S. vegetarians with regard to the few items where uncertainty remains.

We also acknowledge that our data are cross sectional in nature, and no causal inference can be drawn from this type of dataset. The fact that vegetarian status was self-reported may introduce a certain bias that we discussed elsewhere in great detail [68]. In addition to that, it is well known that several self-reported vegetarians in NHANES also consumed meat [20]. One may consider this additional limitation that could contribute to nonsignificant differences in defecation patterns between both groups. Moreover, it is of utmost importance to highlight that the employed dataset dates back to 2007-2010. It is a challenge to compare this sample to "modern" vegetarian populations because "nutritional awareness" has (potentially) increased over the past years among vegetarian cohorts [69]. It is not inconceivable that vegetarians currently pay more attention to adhere to a diverse plant-based diet, including sufficient amounts of fiber.

Ultimately, in light of the small available sample size, we did not stratify our results by gender. Given that some studies reported significant differences between females and 
males with regard to bowel habits [42], this would may have enhanced the quality of our data report. On the flipside, the sample size of the vegetarian groups already appears too low to reliably estimate proportions in even smaller groups.

\section{Conclusions}

To the best of our knowledge, we present the first study that particularly investigated bowel health in a cohort of NHANES vegetarians (2007-2010). The surprising lack of associations between vegetarian status and bowel health items could be explained by the relatively low fiber intake (and the lower moisture intake) in the vegetarian group. The fact that even the vegetarian cohort in this sample did not meet the Institute of Medicine's recommendations for daily fiber intake demonstrates once again America's distressing fiber gap. In comparison with other vegetarian cohorts, U.S. vegetarians consumed substantially less fiber. The relatively small sample size, however, warrants caution, and additional studies are required.

Author Contributions: Conceptualization, M.A.S. and M.L.; methodology, M.A.S.; software, M.A.S.; validation, M.A.S.; formal analysis, M.A.S.; investigation, M.A.S., G.R., A.M. and M.L.; resources, M.A.S., G.R. and M.L.; data curation, M.A.S.; writing—original draft preparation, M.A.S.; writingreview and editing, M.A.S., A.M., G.R. and M.L.; visualization, M.A.S.; supervision, M.A.S., G.R. and M.L.; project administration, M.A.S. All authors have read and agreed to the published version of the manuscript.

Funding: This research received no external funding. The article processing charge was funded by the Baden-Wuerttemberg Ministry of Science, Research and Art and the University of Freiburg in the funding programme Open Access Publishing.

Institutional Review Board Statement: The present study is a negligible risk research that involves existing collections of data that contain only non-identifiable data about human beings. It is a de-identified secondary analysis of freely available data. Research was performed in accordance with the Declaration of Helsinki and approved by the NCHS Research Ethics Review Board (https: / / www.cdc.gov/nchs/nhanes/irba98.htm; accessed on 22 January 2022). NHANES was approved by the National Centre for Health Statistics research ethics review board, and informed consent was obtained for all participants.

Informed Consent Statement: Informed consent was obtained from all subjects involved in the study.

Data Availability Statement: Data are publicly available online (https:/ /wwwn.cdc.gov/nchs/nh anes/Default.aspx; accessed on 22 January 2022). The datasets used and analyzed during the current study are available from the corresponding author upon reasonable request.

Acknowledgments: In memory of Stefan Skaper.

Conflicts of Interest: The authors declare no conflict of interest.

\section{References}

1. Burkitt, D.P. Some diseases characteristic of modern western civilization. Br. Med. J. 1973, 1, 274-278. [CrossRef] [PubMed]

2. Burkitt, D.P.; Walker, A.R.; Painter, N.S. Effect of dietary fibre on stools and the transit-times, and its role in the causation of disease. Lancet 1972, 2, 1408-1412. [CrossRef]

3. Peña-Sánchez, J.N.; Osei, J.A.; Marques Santos, J.D.; Jennings, D.; Andkhoie, M.; Brass, C.; Bukassa-Kazadi, G.; Lu, X.; JohnsonJennings, M.; Porter, L. Increasing prevalence and stable incidence rates of inflammatory bowel disease among first nations: Population-based evidence from a western Canadian province. Inflamm. Bowel Dis. 2021, izab096. [CrossRef] [PubMed]

4. Sanchez, M.I.P.; Bercik, P. Epidemiology and burden of chronic constipation. Can. J. Gastroenterol. 2011, 25, 11B-15B. [CrossRef]

5. O'Keefe, S.J. The association between dietary fibre deficiency and high-income lifestyle-associated diseases: Burkitt's hypothesis revisited. Lancet Gastroenterol. Hepatol. 2019, 4, 984-996. [CrossRef]

6. Modan, B.; Barell, V.; Lubin, F.; Modan, M.; Greenberg, R.A.; Graham, S. Low-fiber intake as an etiologic factor in cancer of the colon2. JNCI J. Natl. Cancer Inst. 1975, 55, 15-18. [CrossRef]

7. Low-Fiber Foods. Available online: https://www.cancer.org/treatment/survivorship-during-and-after-treatment/coping/nutr ition/low-fiber-foods.html (accessed on 20 January 2022).

8. The Do's and Don'ts of a Low-Fiber Diet. Available online: https://www.mayoclinic.org/healthy-lifestyle/nutrition-and-healt hy-eating/in-depth/low-fiber-diet/art-20048511 (accessed on 31 January 2022). 
9. Vanhauwaert, E.; Matthys, C.; Verdonck, L.; De Preter, V. Low-residue and low-fiber diets in gastrointestinal disease management. Adv. Nutr. 2015, 6, 820-827. [CrossRef]

10. Storz, M.A. Lifestyle adjustments in long-COVID management: Potential benefits of plant-based diets. Curr. Nutr. Rep. 2021, 10, 352-363. [CrossRef]

11. Nath, P.; Singh, S.P. 26-Defecation and stools in vegetarians: Implications in health and disease. In Vegetarian and Plant-Based Diets in Health and Disease Prevention; Mariotti, F., Ed.; Academic Press: Cambridge, MA, USA, 2017; pp. 473-481. Available online: https:/ / www.sciencedirect.com/science/article/pii/B9780128039687000265 (accessed on 19 January 2022).

12. Kohnert, E.; Kreutz, C.; Binder, N.; Hannibal, L.; Gorkiewicz, G.; Müller, A.; Storz, M.A.; Huber, R.; Lederer, A.-K. Changes in gut microbiota after a four-week intervention with vegan vs. meat-rich diets in healthy participants: A randomized control trial. Microorganisms 2021, 9, 727. [CrossRef]

13. Djekic, D.; Shi, L.; Brolin, H.; Carlsson, F.; Särnqvist, C.; Savolainen, O.; Chao, Y.; Backhed, F.; Tremaroli, V.; Landberg, R.L.; et al Effects of a vegetarian diet on cardiometabolic risk factors, gut microbiota, and plasma metabolome in subjects with ischemic heart disease: A randomized, crossover study. J. Am. Heart Assoc. 2020, 9, e016518. [CrossRef]

14. Kahleova, H.; Rembert, E.; Alwarith, J.; Yonas, W.N.; Tura, A.; Holubkov, R.; Agnello, M.; Chutkan, R.; Barnard, N.D. Effects of a low-fat vegan diet on gut microbiota in overweight individuals and relationships with body weight, body composition, and insulin sensitivity. A randomized clinical trial. Nutritients 2020, 12, 2917. [CrossRef] [PubMed]

15. Davies, G.J.; Crowder, M.; Reid, B.; Dickerson, J.W. Bowel function measurements of individuals with different eating patterns. Gut 1986, 27, 164-169. [CrossRef] [PubMed]

16. Dwyer, J.T. Health aspects of vegetarian diets. Am. J. Clin. Nutr. 1988, 48, 712-738. [CrossRef] [PubMed]

17. Belsey, J.; Greenfield, S.; Candy, D.; Geraint, M. Systematic review: Impact of constipation on quality of life in adults and children. Aliment. Pharmacol. Ther. 2010, 31, 938-949. [CrossRef] [PubMed]

18. Gilsing, A.M.J.; Weijenberg, M.P.; Goldbohm, R.A.; Dagnelie, P.C.; van den Brandt, P.A.; Schouten, L.J. The Netherlands cohort study-meat investigation cohort; A population-based cohort over-represented with vegetarians, pescetarians and low meat consumers. Nutr. J. 2013, 12, 156. [CrossRef] [PubMed]

19. Storz, M.A. Will the plant-based movement redefine physicians' understanding of chronic disease? New Bioeth. 2020, $26,141-157$. [CrossRef] [PubMed]

20. Juan, W.; Yamini, S.; Britten, P. Food intake patterns of self-identified vegetarians among the U.S. population, 2007-2010. Procedia Food Sci. 2015, 4, 86-93. [CrossRef]

21. Liu, C.; Foti, K.; Grams, M.E.; Shin, J.-I.; Selvin, E. Trends in self-reported prediabetes and metformin use in the USA: NHANES 2005-2014. J. Gen. Intern. Med. 2020, 35, 95-101. [CrossRef]

22. NHANES-About the National Health and Nutrition Examination Survey. 2020. Available online: https://www.cdc.gov/nchs /nhanes/about_nhanes.htm (accessed on 18 January 2022).

23. Kim, H.; Hu, E.A.; Rebholz, C.M. Ultra-processed food intake and mortality in the USA: Results from the third national health and nutrition examination survey (NHANES III, 1988-1994). Public Health Nutr. 2019, 22, 1777-1785. [CrossRef]

24. Leroux, A.; Di, J.; Smirnova, E.; Mcguffey, E.J.; Cao, Q.; Bayatmokhtari, E.; Ziounnikov, V.; Urbanek, J.K.; Crainiceanu, C. Organizing and analyzing the activity data in NHANES. Stat. Biosci. 2019, 11, 262-287. [CrossRef]

25. NHANES Tutorials-Module 3-Weighting. Available online: https://wwwn.cdc.gov/nchs/nhanes/tutorials/module3.aspx (accessed on 18 January 2022).

26. Nickels, S.; Hopf, S.; Pfeiffer, N.; Schuster, A.K. Myopia is associated with education: Results from NHANES 1999-2008. PLoS ONE 2019, 14, e0211196. [CrossRef] [PubMed]

27. NHANES 2007-2008 Demographics Data. Available online: https://wwwn.cdc.gov/nchs/nhanes/search/datapage.aspx?Comp onenTableemographics\&CycleBegin Year=2007 (accessed on 18 January 2022).

28. NHANES 2009-2010 Demographics Data. Available online: https://wwwn.cdc.gov/nchs/nhanes/search/DataPage.aspx?Comp onent=Demographics\&CycleBegin Year=2009 (accessed on 18 January 2022).

29. NHANES 2007-2008 Dietary Data. Available online: https://wwwn.cdc.gov/nchs/nhanes/search/datapage.aspx?Component= Dietary\&CycleBegin Year=2007 (accessed on 18 January 2022).

30. NHANES 2009-2010 Dietary Data. Available online: https://wwwn.cdc.gov/nchs/nhanes/search/datapage.aspx?Component= Dietary\&CycleBegin Year=2009 (accessed on 18 January 2022).

31. Willett, W.C.; Howe, G.R.; Kushi, L.H. Adjustment for total energy intake in epidemiologic studies. Am. J. Clin. Nutr. 1997, 65, 1220S-1228S. [CrossRef]

32. Rhee, J.J.; Cho, E.; Willett, W.C. Energy adjustment of nutrient intakes is preferable to adjustment using body weight and physical activity in epidemiological analyses. Public Health Nutr. 2014, 17, 1054-1060. [CrossRef] [PubMed]

33. Yurtdaş, G.; Acar-Tek, N.; Akbulut, G.; Cemali, Ö.; Arslan, N.; Beyaz Coşkun, A.; Zengin, F.H. Risk factors for constipation in adults: A cross-sectional study. J. Am. Coll. Nutr. 2020, 39, 713-719. [CrossRef]

34. Leung, L.; Riutta, T.; Kotecha, J.; Rosser, W. Chronic constipation: An evidence-based review. J. Am. Board Fam. Med. 2011, 24, 436-451. [CrossRef]

35. AMPM-USDA Automated Multiple-Pass Method: USDA ARS. Available online: https://www.ars.usda.gov/northeast-area/be ltsville-md-bhnrc/beltsville-human-nutrition-research-center/food-surveys-research-group/docs/ampm-usda-automatedmultiple-pass-method/ (accessed on 31 January 2022). 
36. Centers for Disease Control and Prevention, National Center for Health Statistics. National Health and Nutrition Examination Survey MEC In-Person Dietary Interviewers Procedure Manual. Hyattsville, MD: U.S. Department of Health and Human Services, Centers for Disease Control and Prevention. 2008. Available online: http://www.cdc.gov/nchs/data/nhanes/nhanes_07_08/ma nual_dietarymec.pdf (accessed on 5 February 2022).

37. NHANES 2007-2008: Body Measures Data Documentation, Codebook, and Frequencies. Available online: https://wwwn.cdc.g ov /Nchs/Nhanes/2007-2008/BMX_E.htm (accessed on 18 January 2022).

38. NHANES 2009-2010: Body Measures Data Documentation, Codebook, and Frequencies. Available online: https://wwwn.cdc.g ov /Nchs/Nhanes/2009-2010/BMX_F.htm (accessed on 18 January 2022).

39. NHANES 2007-2008: Bowel Health Data Documentation, Codebook, and Frequencies. Available online: https://wwwn.cdc.gov /Nchs/Nhanes/2007-2008/BHQ_E.htm (accessed on 15 January 2022).

40. NHANES 2009-2010: Bowel Health Data Documentation, Codebook, and Frequencies. Available online: https://wwwn.cdc.gov /Nchs/Nhanes/2009-2010/BHQ_F.htm\#BHQ060 (accessed on 15 January 2022).

41. Rockwood, T.H.; Church, J.M.; Fleshman, J.W.; Kane, R.L.; Mavrantonis, C.; Thorson, A.G.; Wexner, S.D.; Bliss, D.R.N.; Lowry, A.C. Patient and surgeon ranking of the severity of symptoms associated with fecal incontinence: The fecal incontinence severity index. Dis. Colon. Rectum. 1999, 42, 1525-1532. [CrossRef] [PubMed]

42. Mitsuhashi, S.; Ballou, S.; Jiang, Z.G.; Hirsch, W.; Nee, J.; Iturrino, J.; Vivian, C.; Lembo, A. Characterizing normal bowel frequency and consistency in a representative sample of adults in the United States (NHANES). Am. J. Gastroenterol. 2018, 113, 115-123. [CrossRef]

43. Lewis, S.J.; Heaton, K.W. Stool form scale as a useful guide to intestinal transit time. Scand. J. Gastroenterol. 1997, 32, 920-924. [CrossRef] [PubMed]

44. Chumpitazi, B.P.; Self, M.M.; Czyzewski, D.I.; Cejka, S.; Swank, P.R.; Shulman, R.J. Bristol stool form scale reliability and agreement decreases when determining Rome III stool form designations. Neurogastroenterol. Motil. 2016, 28, 443-448. [CrossRef]

45. Blake, M.R.; Raker, J.M.; Whelan, K. Validity and reliability of the bristol stool form scale in healthy adults and patients with diarrhoea-predominant irritable bowel syndrome. Aliment. Pharm. Ther. 2016, 44, 693-703. [CrossRef] [PubMed]

46. Jaruvongvanich, V.; Patcharatrakul, T.; Gonlachanvit, S. Prediction of delayed colonic transit using bristol stool form and stool frequency in eastern constipated patients: A difference from the west. J. Neurogastroenterol. Motil. 2017, 23, 561-568. [CrossRef] [PubMed]

47. Zutshi, M.; Tracey, T.H.; Bast, J.; Halverson, A.; Na, J. Ten-year outcome after anal sphincter repair for fecal incontinence. Dis. Colon Rectum 2009, 52, 1089-1094. [CrossRef] [PubMed]

48. Wilson, P.B. Associations between physical activity and constipation in adult Americans: Results from the national health and nutrition examination survey. Neurogastroenterol. Motil. 2020, 32, e13789. [CrossRef] [PubMed]

49. Ditah, I.; Devaki, P.; Luma, H.N.; Ditah, C.; Njei, B.; Jaiyeoba, C.; Salami, A.; Ditah, C.; Ewelukwa, O.; Szarka, L. Prevalence, trends, and risk factors for fecal incontinence in United States adults, 2005-2010. Clin. Gastroenterol. Hepatol. 2014, 12, 636-643. [CrossRef] [PubMed]

50. Markland, A.D.; Palsson, O.; Goode, P.S.; Burgio, K.L.; Busby-Whitehead, J.; Whitehead, W.E. Association of low dietary intake of fiber and liquids with constipation: Evidence from the national health and nutrition examination survey. Am. J. Gastroenterol. 2013, 108, 796-803. [CrossRef] [PubMed]

51. Siller, A.B.; Tompkins, L. The Big Four: Analyzing Complex Sample Survey Data Using SAS ${ }^{\circledR}, \operatorname{SPSS}^{\circledR}, \mathrm{STATA}^{\circledR}$, and $\mathrm{SUDA} \mathrm{AN}^{\circledR}$. Available online: https:/ / www.semanticscholar.org/paper/The-Big-Four-\%3A-Analyzing-Complex-Sample-Survey-Data-Si ller-Tompkins/05b8b99f31aa48835046a4e6317d26b1ed4543fb (accessed on 5 February 2022).

52. Parker, J.D.; Talih, M.; Malec, D.J.; Beresovsky, V.; Carroll, M.; Gonzalez, J.F.; Hamilton, B.E.; Ingram, D.D.; Kochanek, K.D.; McCarty, F. National center for health statistics data presentation standards for proportions. Vital Health Stat. $22017,175,1-22$.

53. Ward, B.W. kg_nchs: A command for Korn-Graubard confidence intervals and national center for health statistics' data presentation standards for proportions. Stata. J. 2019, 19, 510-522. [CrossRef]

54. Sanjoaquin, M.A.; Appleby, P.N.; Spencer, E.A.; Key, T.J. Nutrition and lifestyle in relation to bowel movement frequency: A cross-sectional study of 20630 men and women in EPIC-Oxford. Public Health Nutr. 2004, 7, 77-83. [CrossRef]

55. Panigrahi, M.K.; Kar, S.K.; Singh, S.P.; Ghoshal, U.C. Defecation frequency and stool form in a coastal eastern Indian population. J. Neurogastroenterol. Motil. 2013, 19, 374-380. [CrossRef]

56. Walsh, S.; Hebbelinck, M.; Deriemaeker, P.; Clarys, P. Chapter 11-Dietary patterns in plant-based, vegetarian, and omnivorous diets. In Vegetarian and Plant-Based Diets in Health and Disease Prevention; Mariotti, F., Ed.; Academic Press: Cambridge, MA, USA, 2017; pp. 175-196. ISBN 978-0-12-803968-7.

57. Allès, B.; Baudry, J.; Méjean, C.; Touvier, M.; Péneau, S.; Hercberg, S.; Kesse-Guyot, E. Comparison of sociodemographic and nutritional characteristics between self-reported vegetarians, vegans, and meat-eaters from the nutrinet-santé study. Nutrients 2017, 9, 1023. [CrossRef]

58. Clarys, P.; Deliens, T.; Huybrechts, I.; Deriemaeker, P.; Vanaelst, B.; De Keyzer, W.; Hobbelinck, M.; Mullie, P. Comparison of nutritional quality of the vegan, vegetarian, semi-vegetarian, pesco-vegetarian and omnivorous diet. Nutrients 2014, 6, 1318-1332. [CrossRef]

59. Quagliani, D.; Felt-Gunderson, P. Closing America's fiber intake gap: Communication strategies from a food and fiber summit. Am. J. Lifestyle Med. 2017, 11, 80-85. [CrossRef] [PubMed] 
60. Yang, J.; Wang, H.-P.; Zhou, L.; Xu, C.-F. Effect of dietary fiber on constipation: A meta analysis. World J. Gastroenterol. 2012, 18, 7378-7383. [CrossRef] [PubMed]

61. Anti, M.; Pignataro, G.; Armuzzi, A.; Valenti, A.; Iascone, E.; Marmo, R.; Lamazza, A.; Petaroli, A.R.; Pace, V.; Leo, P. Water supplementation enhances the effect of high-fiber diet on stool frequency and laxative consumption in adult patients with functional constipation. Hepatogastroenterology 1998, 45, 727-732. [PubMed]

62. Arnaud, M.J. Mild dehydration: A risk factor of constipation? Eur. J. Clin. Nutr. 2003, 57, S88-S95. [CrossRef] [PubMed]

63. Huang, L.; Jiang, H.; Zhu, M.; Wang, B.; Tong, M.; Li, H.; Lin, M.-b.; Li, L. Prevalence and risk factors of chronic constipation among women aged 50 years and older in Shanghai, China. Med. Sci. Monit. 2017, 23, 2660-2667. [CrossRef] [PubMed]

64. Storz, M.A. What makes a plant-based diet?A review of current concepts and proposal for a standardized plant-based dietary intervention checklist. Eur. J. Clin. Nutr. 2021, 13, 3952. [CrossRef]

65. Lin, C.L. Reply From Author for Letter to the Editor Concerning: Stroke and Diets: A review. Tzu Chi Med J. [Epub Ahead of Print]. Available online: https:/ / www.tcmjmed.com/preprintarticle.asp?id=325834 (accessed on 15 January 2022).

66. Sobiecki, J.G.; Appleby, P.N.; Bradbury, K.E.; Key, T.J. High compliance with dietary recommendations in a cohort of meat eaters, fish eaters, vegetarians, and vegans: Results from the European prospective investigation into cancer and nutrition-Oxford study. Nutr. Res. 2016, 36, 464-477. [CrossRef]

67. Vegetarian Times 2008. Vegetarianism in America. Available online: https://www.vegetariantimes.com/uncategorized/vegetari anism-in-america / (accessed on 31 January 2022).

68. Storz, M.A.; Müller, A.; Lombardo, M. Diet and consumer behavior in U.S. Vegetarians: A national health and nutrition examination survey (NHANES) data report. Int. J. Environ. Res. Public Health 2021, 19, 67. [CrossRef]

69. Leitzmann, C. Vegetarian nutrition: Past, present, future. Am. J. Clin. Nutr. 2014, 100, 496S-502S. [CrossRef] 